\title{
Программное средство расчета оснований фундаментов при использовании многолетнемерзлых грунтов в качестве оснований по I принципу
}

\author{
Назаров Т.А., Бочуров В.Б., магистранты, \\ Северо-Восточный федеральный университет, \\ 2. Якутск \\ E-mail: Nazarovta@yandex.ru; \\ baaska1995@gmail.com
}

\section{Научный руководитель: к.т.н., доцент Посельский Ф.Ф.}

В настоящее время в системе автоматизированного проектирования (САПР), существует проблема отсутствия программного обеспечения расчета оснований и фундаментов на многолетнемерзлых грунтах. Сейчас в Якутии для расчета несущей способности оснований и фундаментов на практике используется единственная программа «Svai/РC», официально разрешенная для расчетов ГАУ «Управление государственной экспертизы проектной документации и результатов инженерных изысканий в строительстве $\mathrm{PC}(Я) »$. Программа «Svai/PC» была разработана в 90-х годах и соответствует старым нормам (СНиП 2.02.04-88). Между тем многолетняя мерзлота занимает площадь около 10 млн. км², или более $60 \%$ территории России [2] и именно в этой обширной территории расчеты оснований и фундаментов ведутся по СП 25.13330.2012 «Основания и фундаменты на вечномерзлых грунтах». Из этого следует, что актуальность проблемы является достаточно масштабной на территории Российской Федерации. Поэтому мы решили создать программу, которая рассчитывала бы несущую способность оснований фундаментов на многолетнемерзлых грунтах по актуальным на данный момент нормам.

Целью нашей работы является полное автоматизирование расчета оснований фундаментов на многолетнемерзлых грунтах.

Программа «PilePermafrost» закодирована в языке программирования Borland Delphi и может выполнить следующие расчеты:

1. Расчет среднегодовой температуры и глубину сезонного оттаивания и промерзания грунта по методике приложения Г [1];

2. Расчет несущей способности оснований фундаментов при использовании многолетнемерзлых грунтов по принципу I (с сохранением мерзлого состояния грунтов) по СП 25.13330.2012.

Сама программа состоит из трех окон:

На начальном окне (рис.1) рассчитываются необходимые данные, такие как среднегодовая температура и глубина сезонного оттаивания и промерзания грунта, которые используются в дальнейшем для расчета оснований фундаментов в программе.

Исходные данные для расчета несущей способности вводятся в окне «Ввод исходный данных» (рис. 2). В нем задаются данные инженерно-геологических изысканий, тип поверхности фундамента, геометрические характеристики сваи и здания, климатические данные, особенности технологии устройства сваи и другие данные. Для удобства, введенные данные можно отобразить в виде инженерногеологического разреза с помощью кнопки «Нарисовать». 
Для расчета несущей способности нужно сохранить введенные данные и открыть в окне «Расчет несущей способности» сохраненный файл. Введенные данные сохраняются в текстовом файле (*.txt).

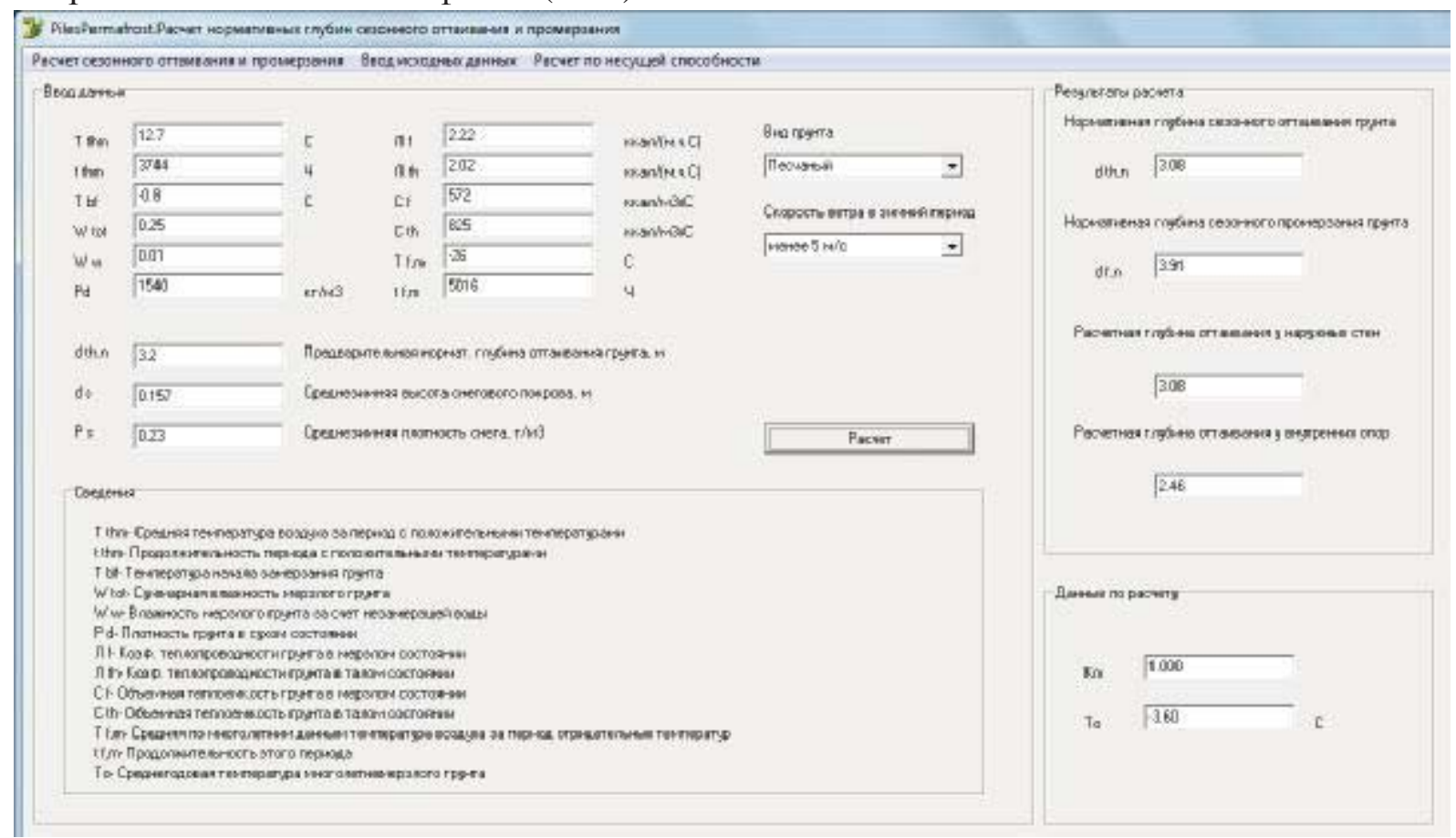

Рис. 1. Окно расчета глубин сезонного оттаивания и промерзания

Далее программа рассчитывает расчетное сопротивление грунтов сдвигу по поверхности смерзания Raf и по грунту или грунтовому раствору Rsh. Из них выбирает наименьшее значение. Затем определяет расчетное давление под нижним концом сваи $R$.

Расчетные значения прочностных характеристик принимаются в соответствии с табличными данными, приведенными в приложении В [1] в зависимости от их физических характеристик, составов и температур.

В программе написана универсальная подпрограмма, которая делает биполярную интерполяцию табличных данных [1]. Эти табличные данные находятся в папке программы в формате *.txt.

В результате расчетов программа выводит таблицу промежуточных данных, эпюру несущей способности Raf·Aaf, эпюру температуры Tz,cp, эпюру температуры $T z$, а также использованные при расчете исходные данные (рис. 3.).

Положительными сторонами программы «PilePermafrost» являются:

1) Расчет по действующим и актуальным на сегодняшний день нормативам, ГОСТам и сводам правил.

2) Вывод промежуточных результатов. По сравнению с нашей программой, «Svai/РC» в отчете не отображает промежуточные результаты расчетов, а выводит только конечный ответ, что весьма затрудняет проверку расчетов программы. 


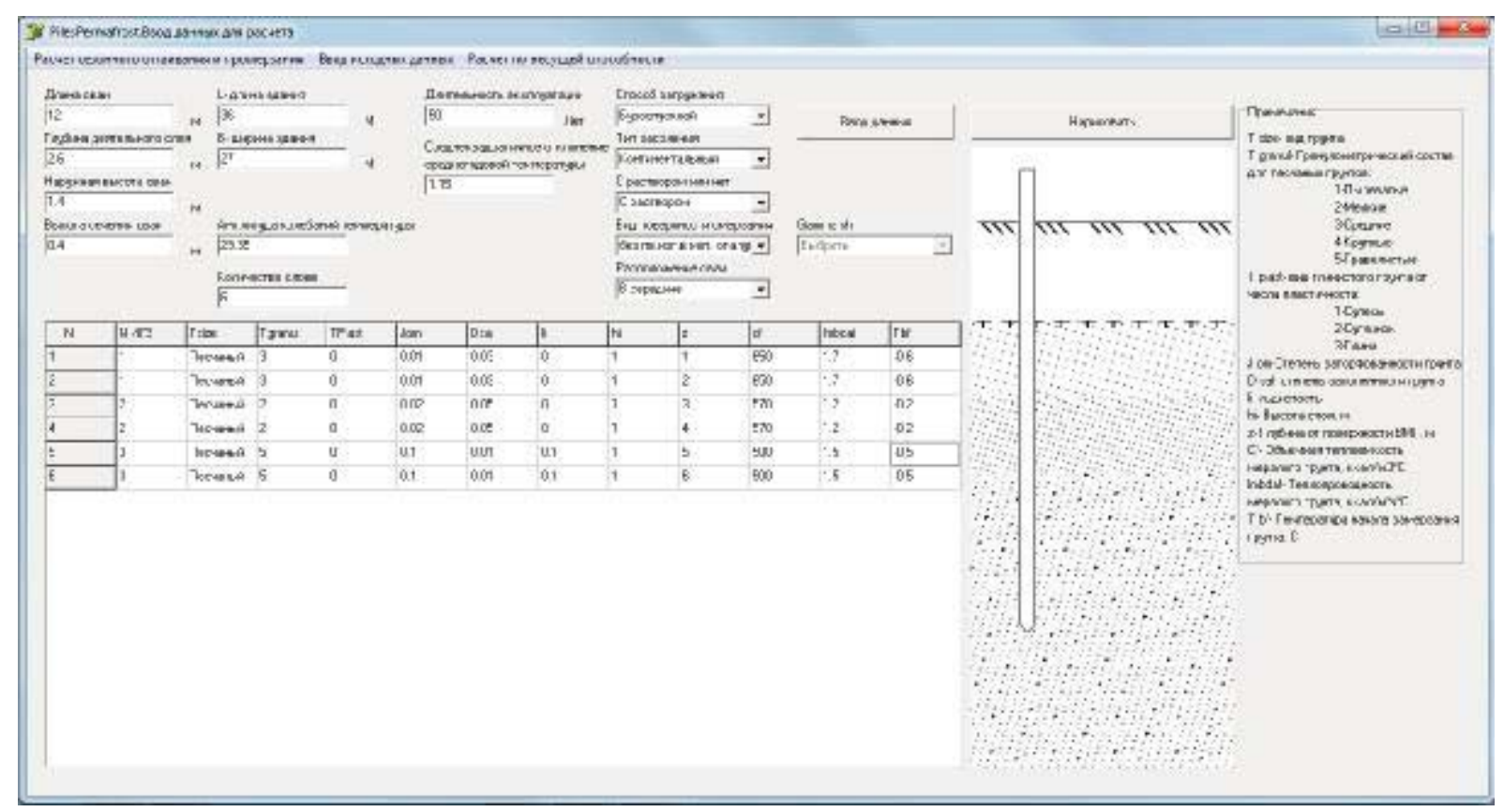

Рис. 2. Окно ввода исходных данных

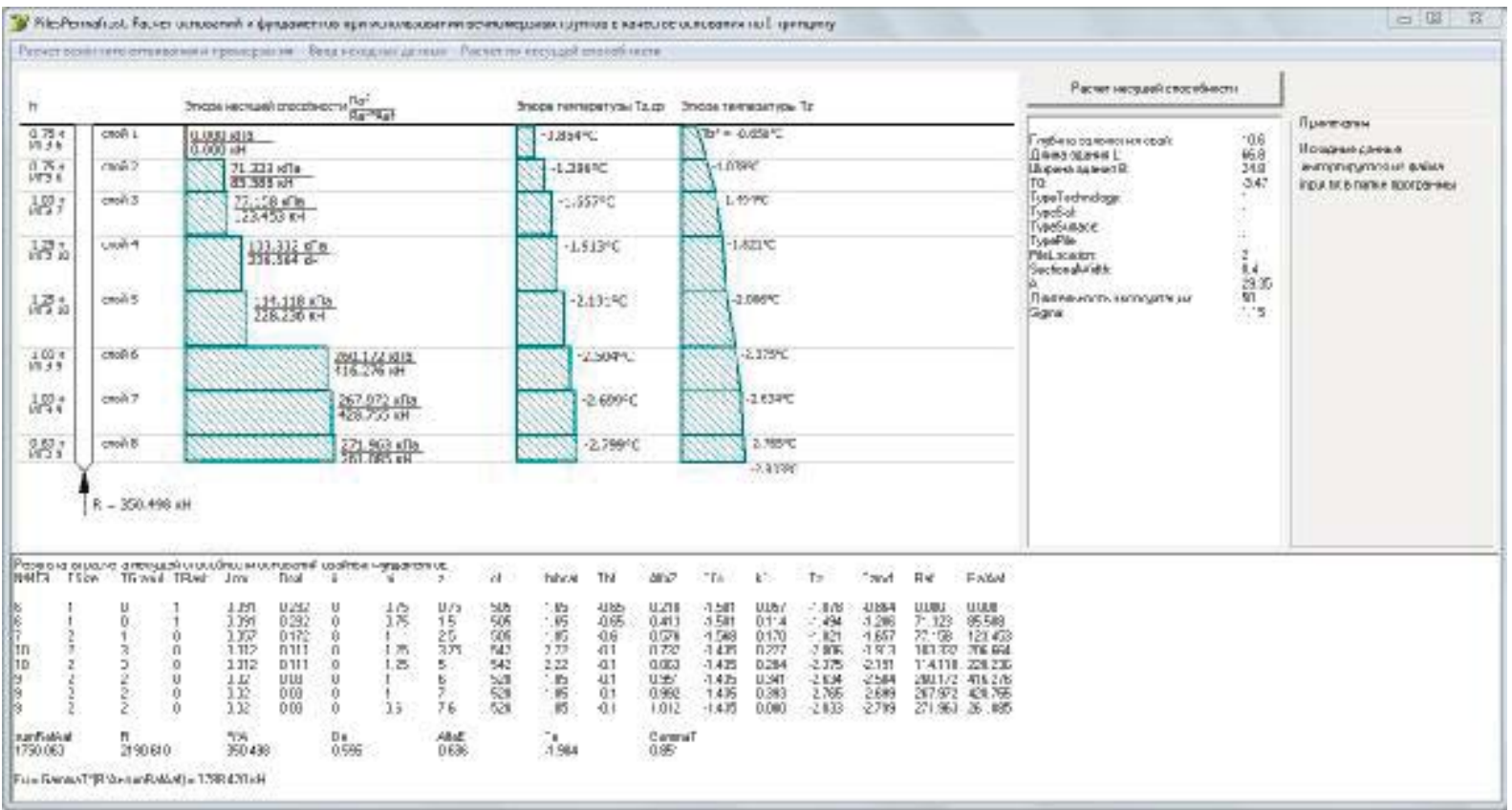

Рис. 3. Результаты расчета несущей способности

3) Программа разработана на актуальной среде Borland Delphi и программа не конфликтует с новейшими операционными системами.

4) Рабочее окно программы разработано таким способом, чтобы пользователю было максимально комфортно и просто вводить данные и посмотреть результаты. Все вводные данные сопровождаются комментариями и графическими пояснениями, что весьма удобно для пользователя.

Провели тестирование программы ручным расчетом оснований фундаментов на заторфованных и засоленных грунтах. Результаты тестов приведены в таблице 1. 
Сравнение тестовых расчетов

\begin{tabular}{|l|l|l|l|l|}
\hline \multirow{2}{*}{$\begin{array}{c}\text { Номер тестового } \\
\text { расчета }\end{array}$} & \multicolumn{4}{|c|}{ Результаты расчета, кН } \\
\cline { 2 - 5 } & \multicolumn{2}{|c|}{ Ручной расчет } & \multicolumn{2}{c|}{ Расчет по программе } \\
\cline { 2 - 5 } & $R \cdot A$ & $\sum R a f \cdot A a f$ & $R \cdot A$ & $1696, A a f$ \\
\hline Тест 1 & 413,9 & 1668,738 & 413,867 & 1750,06 \\
\hline Tест 2 & 350,5 & 1750,056 & 350,498 & \\
\hline
\end{tabular}

Программа «PilePermafrost» все еще находится в стадии разработки. В данный момент рассматривает все основные положения расчета СП 25.13330.2012, но не учитывает особенности проектирования оснований фундаментов на сильнольдистых грунтах. В ближайшем будущем планируется полностью доработать программу по расчету оснований и фундаментов на многолетнемерзлых грунтах по 1 принципу.

\section{Список литературы:}

1. СП 25.13330.2012. Основания и фундаменты на вечномерзлых грунтах. Актуализированная редакция СНиП 2.02.04-88. - Введ. 2013-01-01. - М.: Минрегионразвития, 2013 - 117 с.

2. Многолетняя мерзлота [Электронный ресурс]. - Режим доступа: http://www.novrosen.ru/Russia/nature/chill.htm. - (Дата обращения 01.03.2017)

\section{Влияние комплексной добавки ЦМИД-4 на бетонную смесь и бетон}

Одарич Д.В., студент, Технический институт (филиал) Северо-Восточного федерального университета, 2. Нерюнгри

Научный руководитель: стариий преподаватель Кулигина Е.C.

ЦМИД-4 представляет собой многокомпонентную комплексную добавку для бетона, включающую в себя комплекс микронаполнителей, химических и поверхностно- активных компонентов. Разработчиком является ЗАО «НП ЦМИД» г. Санкт-Петербург.

Добавка ЦМИД-4 - многофункционального, пластифицирующего, воздухововлекающего действия, с четко выверенными пропорциями компонентов и не требует введения в бетонную смесь дополнительных добавок.

Разработчик гарантирует следующие эффекты от применения:

- пластификация - получение высокоподвижных бетонных смесей с ОК 25 см при низких В/Ц до 0,36. 